\title{
Teaching IT Project Management to Postgraduate Business Students: A Practical Approach
}

\author{
Arthur Tatnall and Gina Reyes \\ Centre for International Corporate Governance Research and \\ School of Information Systems, Victoria University, Australia
}

\section{Arthur.Tatnall@vu.edu.au Gina.Reyes@vu.edu.au}

\section{Executive Summary}

While most Information Systems (IS) professionals spend much of their time in the implementation or management of projects, the curriculum of university Information Technology (IT) courses does not always reflect this. While most university IT courses cover some aspects of project management, some do not go into this topic in any depth, and many make this a wholly theoretical exercise, particularly at the postgraduate level. We have found that students, even postgraduate students, often lack a practical frame of reference and so if the material is presented only in a theoretical manner, some of the nuances of project management issues escape them.

In the paper we describe and advocate a practical approach to teaching IT Project Management to postgraduate business students from many different disciplines. In particular, we advocate the construction of student assignments designed to make use of project management software to handle the on-going management of projects as well as project planning, the use of online student exercises, and student class presentations as a way of achieving this. The paper outlines the approach used at Victoria University and relates some of the student feedback we have received.

The paper is set out in five sections:

- The Importance of IT Project Management. In this section we examine the importance of this subject area and the need to include it in postgraduate IT and other business courses.

- Teaching IT Project Management Concepts. Next we discuss some of the teaching concepts and issues involved in relation to a learning model.

- IT Project Management Subject Structure. This section describes the subject 'IT Project Management' taught at Victoria University, detailing the content and the assignments.

- Student Evaluation. Surveys have been conducted at the end of each semester for the last three semesters on what students thought of the subject and what they thought they had learned. This section describes and analyses this student feedback.

- Conclusion. Our approach to teaching 'IT Project Management' involves both lectures and

Material published as part of this journal, either on-line or in print, is copyrighted by the publisher of the Journal of Information Technology Education. Permission to make digital or paper copy of part or all of these works for personal or classroom use is granted without fee provided that the copies are not made or distributed for profit or commercial advantage AND that copies 1) bear this notice in full and 2) give the full citation on the first page. It is permissible to abstract these works so long as credit is given. To copy in all other cases or to republish or to post on a server or to redistribute to lists requires specific permission and payment of a fee. Contact Editor@JITE.org to request redistribution permission. practical assignments. It gives particular stress to the use of project management software to plan, monitor and control a project. We conclude that it works well with both postgraduate IT and general business students.

Keywords: Information technology, project management, project management software, university curriculum 


\section{Introduction - the Importance of IT Project Management}

Many university IT-related courses teach a little project management, sometimes at undergraduate, sometimes at postgraduate level. In undergraduate computing courses in Australia these concepts are often cursorily handled in Systems Analysis or Systems Design subjects (for example see: (RMIT University, 2005; Victoria University, 2005)). The computing industry, however, is giving increased attention to the use of project management techniques to improve the quality of IT projects and reduce their likelihood of failure (McCarthy, 2004; Xia \& Lee 2004) and the Australian Computer Society's guidelines for university computing courses (Australian Computer Society, 1997) now makes knowledge of IT project management a core requirement.

Most of the internationally used Information Systems Model Curriculum guidelines (such as (Gorgone, Davis, Valacich, Topi, Feinstein \& Longenecker, 2002)) give significant weight to teaching IT project management. Of particular interest to this paper is the postgraduate curriculum model - MSIS 2000 (Gorgone \& Gray, 2000) which includes a full unit on 'Project and Change Management'.

Furthermore, there has been a change in the way that some management theorists view the nature of management. Turner (1993), for instance, writing in the context of project management in general, has suggested that much of what we now consider in the category of management in the traditional sense could be better handled as a number of discrete projects undertaken using project management techniques. Project management differs from many other topic areas as it is built on concepts of change, and tasks and resources that need to be manipulated (Tatnall \& Shackleton, 1995). There are technological issues to consider of course, but by its very nature project management also involves many other socio-technical factors.

Project management thus involves much more than just project planning and scheduling, and is more primarily concerned with controlling the on-going project during its whole life. This aspect of project management is, however, given little attention in most university courses or model curricula. In fact, on reading through the various IS curriculum models it would appear that the main emphasis is on project planning, and only cursory attention is given to on-going project monitoring and control. What tends to be taught is thus just the 'planning' of projects - Gantt and PERT charts are drawn, sometimes using project management software, to produce a list of the interrelated project tasks (Shackleton \& Tatnall, 1995; Tatnall \& Shackleton, 1996).

This paper describes the approach used by the authors to teach IT Project Management to postgraduate business students at Victoria University, and provides details of our evaluation of how students take to this approach. It describes the subject BCO6656 - IT Project Management, a core subject for the Master of Business (Information Systems) degree and an elective in other business masters programs at Victoria University. Our students include all those undertaking a postgraduate course in Information Systems, but also some students studying the MBA and some studying management, marketing, accounting, finance, hospitality, tourism or economics courses. While many of the students are Australian we have a substantial number also from China, India and Pakistan, and a few from various other parts of the world.

This paper is set out in several sections, the next providing a discussion of some of the educational theory and issues encountered in teaching IT Project Management. The section that follows outlines the structure and content of the subject and describes the assignments. Next we describe our evaluation of how the students handled the subject; what they thought they had learnt in the lectures, what they thought of each of the assignments and how useful they thought the material to be. Finally we conclude with a brief summary of our findings and a reiteration of the importance of teaching IT Project Management. 


\section{Teaching IT Project Management Concepts}

While IT as a discipline of study has been around for the past few decades, the challenges of teaching IT remain. Hosseini (1993) identified challenges of teaching Management Information Systems (MIS) concepts to students, saying that the abstract nature of concepts surrounding the development and management of IT systems make these concepts hard to teach in the classroom. He states that often, students lack a practical frame of reference so that the various nuances of IT issues escape them, especially if these issues are those that are dealt with at a managerial level.

Hosseini bases this statement on conclusions reached by Piaget (1974) when he proposed his model of 'cognitive information processing'. The assertion made in this model is that in order for a person to understand some new concept or piece of information, this new information must be integrated into the person's own schemata of knowledge. In other words, the new concept or idea must in someway be linked to what the person already understands or knows so that they can see how it all fits in with their view of reality. Piaget named this personal view of reality a 'logicomathematical structure' (LMS).

This model helps us understand the difficulty of teaching various IT-related concepts, such as IT Project Management, to students. Many of the issues dealt with are abstract, such as understanding why a project is terminated early, or how to manage the various levels and degrees of risk. Many of the issues discussed require an existing 'model of reality' gained usually through professional experience and through the use of certain methodologies and tools. We have noted that many students, even at a postgraduate level, do not have this experience and thus find it hard to identify and comprehend the important issues.

This view is also congruent with Biggs' (1999) concept of 'constructivism' in teaching, where this refers to a student's effective learning: learning that will take place if a student has support in constructing meaning from the subject content. This 'meaningfulness' is evident in a student's 'need-to-know'. Biggs suggests that when students have this appetite for knowledge, they will focus on learning as much detail as possible of the underlying concepts, reasons, and applications. He refers to this as a 'deep approach' to learning (Reyes \& Gabb, in press), as opposed to a 'surface' approach where students memorise facts and pieces of knowledge only to forget them later on.

The challenge in teaching IT Project Management therefore is in being able to provide, in a short period of time, a basic LMS that students can integrate into their own knowledge so that they can understand and apply IS concepts. In Biggs' terms, this means providing a learning environment for students to engage in the deep approach to learning. Thus Hosseini (1993) recommends the following approaches may be used to teach Information Systems courses:

- Lecture

- Question/answers related to the lecture material

- Short case studies with questions

- Long case studies with questions

- Hands-on computer assignments using software

- Projects that require students to work with an external organisation to apply the concepts and techniques learnt in class

It can be argued that these challenges and approaches also apply to teaching IT Project Management. For a project management course to be successful, theoretical and practical components should be integrated, allowing students to apply the theory they have learned in as near to a reallife situation as possible (van Weert \& Tatnall, in press). The teaching of project management lends itself particularly well to the use of practical work to reinforce theory, and use of a large, 
on-going case study sets up a number of complexities that can reproduce real-world experiences. Little and Margetson note that:

"No amount of learning about something will, alone, prepare a student adequately to practise a particular skill or to make use of knowledge in a sensible, appropriate, and effective way. This is even more so when the learning in question concerns the design, development, and operation of computer-based information systems." (Little \& Margetson, 1989, p. 131)

In designing a postgraduate subject on IT Project Management, a useful starting point would be to look at MSIS 2000 (Gorgone \& Gray, 2000) in conjunction with the Project Management Body of Knowledge (A guide to, 2004), and this appears to be how many such subjects are developed. Our investigations, however, suggest that there is considerable variation in the way that the theoretical and practical aspects of the material are handled. While many university courses make use of project management software (such as Microsoft Project), most seem to use this only for project planning and give little consideration to the on-going IT project. This is one place where our subject differs from many others in giving significant attention in the practical work to monitoring and control of the on-going project and also to managing multiple projects.

\section{IT Project Management Subject Structure}

Like most university subjects, IT Project Management at Victoria University is delivered in a two hour lecture and a one hour workshop each week, for a twelve week semester. The lectures cover the following topics:

1. The nature of projects:

a. Project Management Body of Knowledge

b. Defining the problem - the project goal

2. Project management concepts:

a. Methodologies

b. Software tools

c. Managing multiple projects

3. Project risk assessment, project chartering

4. Project estimation

a. Developing the project plan and schedule

b. Project cost control

5. Human Aspects:

a. Building the project team

b. Management of conflict

6. Software/Information Systems issues

a. Software engineering project case studies

b. Implementation difficulties

7. Software and project quality

8. Reporting on project status

a. Project monitoring and control

b. Handling multiple (concurrent) projects

9. Project termination

10. Why some projects fail

11. Innovation and the management of technological change

a. Information systems and change, resistance to change

b. Innovation models (diffusion, translation)

12. Summary and final multi-choice test

Because the subject is available to both IT students and others taking courses ranging from MBAs to Marketing, Hospitality or Accounting it is important that the content does not rely on much 
prior knowledge of IT or IT concepts. Topics such as Software Issues and Software Quality are designed to achieve this.

Although lectures are important, in this paper we are particularly addressing that part of the subject that relates to workshops and assignments. Assessment in this subject consists of three major assignments: a practical case study exercise in three parts (project charter, project planning, project monitoring and control) using Microsoft Project, a series of online exercises, and a formal oral presentation. There is also a multi-choice test ( 30 questions done in 1 hour) to cover the lecture content. Questions on this test are designed to cover more than just content knowledge, with many questions aimed at understanding and some at interpretation.

\section{Assignment 1 (40\%)}

Assignment 1 has students working in groups of two to plan, monitor and control a case study project using Microsoft Project software. In the case study, each group of students is employed as (joint) project manager for a Project Management company that contracts its services to other companies in need of IT project work. (A sample assignment is provided in the Appendix.)

This assignment has three parts. In the first part (5\%) students analyse the case study to determine project risks and to make estimates that will lead to the production of a project charter. In the second part (20\%) the case study proceeds with the award of the project contract. Students now go on to produce a full project plan with all resources and costings, using Microsoft Project. Their 'deliverables' for this part of the assignment include a business letter to the project client summarising the important items in the budget and schedule. This should, however, include only information that is relevant to the client, and be expressed in a form that will be understood by the client. The other deliverables are contained in a letter to the Director of the project company that will include: an executive summary, a list of any assumptions made and special requirements for the project, a detailed Gantt chart showing the critical path and with a baseline project schedule, a Network diagram (PERT chart) with no dangling tasks, a Microsoft Project summary report and a series of other reports showing detailed costing and resource usage.

It is difficult to provide an example with enough complexity to enable students to effectively come to grips with some of the more important aspects of project management and often, in subjects like this, the examples provided are so simple that they can be solved by students working with only pen and paper. We attempt to choose a case study of sufficient complexity so that project planning - in the first and second parts of this assignment, is not just a trivial exercise, but is also not so complex as to be impossible to achieve in the time available. Our experience has shown that somewhere around 30-40 tasks are about right, but that it is very important to insist on the use of summary tasks as well as detail tasks. Case studies have included: an office system for a group of business consultants specialising in company law, a new administrative system for a secondary college, a control and management system for a company that manufactures industrial robots for use in applications such as warehouse item picking and specialised component assembly, a management system for a company that manufactures large commercial weighing machines, customisation of an ERP system along with installation of relevant office infrastructure for a box manufacturing company, and a data mining system for a group of medical general practitioners. We have also used assignments with multiple (smaller) projects including one involving the following four projects, all running together: CustomLine Auto Parts - conversion of a legacy database to Oracle, Celtic Creations - documentation for a TPS, SuperFast Consultancy Services - fast dial-up directory services and a PC-LAN installation at the Department of Administrative Affairs.

After this part of the assignment has been submitted, our case study project 'starts' and the third part of the assignment (15\%) involves project monitoring and control over three or four weeks. 
(The case study project is chosen with a start date four weeks from the end of semester and a finish date at the end of semester so that this monitoring process occurs in 'real-time' during this period.) In these weeks the first ten minutes of each lecture is given over to a 'project meeting' in which the lecturer outlines project progress over the past week. The purpose of these sessions is to simulate (as far as this is possible in a lecture of over 60 students) regular project team meetings. The project meetings examine the progress of each task performed (or being performed) that week: did it start on time? did it use the resources planned? did it take the time estimated? did it finish on time? and so on. Students then update their projects (in Microsoft Project) with the changes and extra information provided, and submit a report to their tutor the following week containing: a tracking Gantt chart, summary report, budget report, report on slipping tasks, and a correction for any over-allocation of resources that may have occurred.

Typical project meeting scenarios for out of control tasks include:

- A programmer phoning in to tell us she has the flu and will be absent for at least one week, and her replacement not being able to start work for 3 days due to other commitments.

- A problem with purchase of PC equipment - it took longer than expected to finalise arrangements with the supplier and so delivery has consequently been delayed.

- Due to unforseen complexity in customising a program to control a robot this task took four weeks to complete rather than the three weeks estimated.

- Electricians have discovered a fault with the earth leakage detector in the switch board - the detector can be replaced but this will require a shut-down of the whole plant for one day and will cost an additional \$2000, not including the loss of production.

- The desktop computer support people will not be available this week because they are engaged on another project that is running behind schedule.

- Our client has requested some extra work (additional tasks) to be included in the project.

- One of your staff was involved in an altercation with an employee of the client - your project team member was accused of interfering with the operation of an injection moulding machine, and as a result the factory safety office ordered all your staff off the site immediately.

\section{Assignment 2 (15\%)}

Assignment 2, done individually, involves having students answer questions related to the lecture material. These questions are provided online via the e-mail module of WebCT. The e-mail approach was chosen for its ease-of-use and for the personal effect it achieved: it seemed that students were addressed individually in the e-mail. Each week (over a ten week period), after the lecture, students received an e-mail asking them to search for relevant, reliable and useful information on the Internet regarding a particular issue. Students were to explain how they found the information, why they found it relevant to the issue, and how it was useful. Each appropriate reply that fully answered the questions was awarded $1 \frac{1}{2}$ marks. The aims of these exercises were:

- To have students exercise their knowledge and fact-finding skills on the Internet.

- To develop their own sense of knowledge evaluation: how they know something is worthwhile knowing, and is reliable as truth.

- To enhance their written communication skills in presenting what they had found and arguing why it is useful.

\section{Assignment 3 (15\%)}

The third assignment requires small groups of students to give a short (10-15 minute) in-class presentation on an IT project management topic. A list of topics is provided with students having some freedom to choose a topic of interest to them, provided that each topic is chosen only once. Each topic includes suggested references from journals, but the students are free to use these or not and to include other material if they wish. Topics include: the project manager and project 
teams, human aspects and project culture, project estimation, assessing and managing risk in IT projects, managing software quality, IT project success and failure, terminating a project, software development and issues, project management and technological change, comparisons of project management software, software project case study, and project management paradigms.

Presentations are given during the lecture time in the weeks following the related lecture. Part of the assessment requires students to relate their discussion back to relevant aspects of the appropriate lecture.

\section{Evaluation of Student Feedback}

In second semester 2004 the sixty-eight postgraduate students studying IT Project Management were a mixed group. Although the majority were undertaking a Master of Business in Information Systems the group included MBA, Marketing, Finance and eCommerce students, a number of students from the Graduate Diploma of Business Computing and a couple studying International Trade. This section of the paper outlines responses of these students, combined with the sixtyseven students from first semester 2004 and seventy-seven from second semester 2003, to surveys conducted in class time at the end of each semester.

We conducted these surveys to find out:

- What the students thought of the subject content, and whether it was meeting their needs and expectations.

- What they thought about the value of each of the assignments, and in particular the one involving monitoring and control of the on-going project.

- What they thought they had learned from the subject.

- How they found working with Microsoft Project.

- Any suggestions for changes to the subject.

The survey has some questions with Likert scale responses and others that allowed an open-ended response. In each case it was completed by around $80 \%$ of the students. Some additional questions on the online assignment were also given online.

\section{Subject Content - lectures and assignments}

When asked what they found to be the most interesting lecture topics the clear winner was Project Failure. Other popular topics included (in order): project success, risk, termination, quality, human aspects, change, and the role of the project manager. They found the following topics the most difficult: risk, estimation, project planning, human aspects and change management. When asked what topics should be left out next semester the overwhelming response was none - if anything, please add more!

Students generally found the mix of theory and practical work to be very appropriate:

"A very good subject designed to develop your understanding and interaction with project management."

"Overall the assignments were interesting and worthwhile."

"I really learned some useful technology and knowledge from this subject - especially from the practical work."

"It is an interesting subject - I think even more time should be put on some practices of PM because sometimes the theory is a bit dull."

"The subject finished too early - maybe l'm saying this because it was an interesting one."

"The subject was enjoyable and opened my eyes up to the big picture."

"I like the idea that 'the longer a project takes the more likely it will not succeed', this will stick with me for the remainder of my working life." 


\section{Problems with Microsoft Project}

As described above, the first assignment involved planning, monitoring and controlling a case study project using Microsoft Project software. Students found this the most interesting assignment (4.3 out of 5.0 on a Likert scale) but also the most difficult (3.8). It is not easy to use project management software, and most people find it much harder to use than Excel, for instance. Another problem is that the starting threshold is much higher for project management software tools than for most other software packages (Tatnall \& Shackleton, 1993). To use a word processor the user need have little more than knowledge of how to write, yet to use a project management package they must have a sound knowledge of the principles of project management as well as of the software package being used.

Microsoft Project at first appears to be a package like Excel or any other Windows application and a good deal of skills transfer to its use seems to be possible. It is not until you have tried to make serious use of the software however, that its complexities and idiosyncrasies appear. An experienced user can get around most of the difficulties, but students often have problems with some aspects of the package. For instance, they have trouble with task constraints until they realise that the only safe way to handle these is to set all tasks (where possible) to begin 'As soon as possible'. The first time that the critical path seems to vanish entirely before your eyes can be a little disconcerting until you realise that it is due to the accidental setting of one of these task constraints to something like 'Must start on'. When you discover this, it becomes obvious why the path is indeed no longer critical. The logic of why some of the other possibilities, such as 'Start no later than', also create problems can be difficult for new users to understand. The fact that dragging a task on the Gantt chart using the mouse will change its task constraint from 'As soon as possible' to 'Must start on' is something you can allow for if you know about it. Unfortunately the Microsoft Project documentation does not make this at all clear to new users.

Student comments about using Microsoft Project included:

"It is troublesome and tedious sometimes."

"It was an interesting encounter to learn MS Project."

"It was good for me to do this subject - now I am able to work MS Project and organise any project."

"It is a bit tricky sometimes - sometimes you need to spend a lot of time to fix the projects and it is easy to make the project go wrong and get mixed up if you do not do it the proper way."

\section{On-Going Management and Control}

Students found the on-going project monitoring and control part of the assignment quite different to anything they had done before in other university assignments. The first thing that was apparent was that the degree of uncertainty created by the changes was new to most students. All their previous university assignments involved a fixed scenario, not one that changed each week. When producing their original project schedule students were told to expect changes due to 'unforseen circumstances', but it was not until the first of these changes was made that students became aware of the uncertainty.

To provide a 'level playing field' for the students we took the precaution of providing them with an 'official' solution to the project planning part of the assignment before commencing the ongoing monitoring and control part, so that any students who did not get this part of the assignment right would still be able to continue with the rest. Some students expressed concern, and even mild resentment, that much of their good work had to be redone to correct problems that were not of their own making. By the end of the semester though, most students appreciated that the project plan they had produced originally was not really the final product they had at first thought, and several commented that this was a good lesson in the realities of life in the real world. 
Student responses to this aspect of the subject included:

"Got frustrated with the need to change things I thought I had got right in the planning but I suppose this is reality."

"Reinforced skills - more confident with each stage."

"Good to have a PM assignment that is not just about Gantt charts but gives you a chance to do some real problem solving."

"Absolutely hated it. Found it hard to modify the changes. Would rather start from the beginning."

"Ideal way to test the students' capacity to manage change elements in a project."

"It really forced me to understand and learn the subject by using this method. It also showed that PM is a necessary part of applications development."

"Really good, this is what project management is about."

\section{The Online Assignment}

In this assignment the students sent in replies on a weekly basis ranging from 50 to 200 words and over $80 \%$ answered these messages every week. When students were asked if the online work helped them understand the lecture material and if they learnt more about project management, responses included:

"The online work was really helpful as I was able to find up-to-date material on the various issues related to the lectures, thus I was able to understand the content of the lectures better."

"Absolutely yes, the reason is that I can study and deeply know why this project [failed or succeeded] and can learn how to avoid causes which contribute to project failure and learn how to conduct project control, monitoring, and project evaluation. Especially when I was doing case study searching, I have great interest in learning how the other project experts analysed and discussed the reasons which contributed to project failure and what the opinions of the experts were on these."

"Such activities are of interest and helpful for us to find some additional material related to the theory taught in the lecture. After all, 2 hour lecture is insufficient to cover the whole topic of project management. Thus through e-mail work, it allows us to read more."

"It really enriched my learning experience."

"Yes, it did as I browsed over the Internet and read more articles before I answered the online question. The online work allowed me to answer the questions in various ways that resulted in different views to provide information. I think online work gives more flexibility in how to look at a project issue."

"It was a new experience for me - it's different, and a good way to have some discussion on the subject."

From a lecturer's point-of-view, the use of the online work was beneficial because it gave the students another way of engaging with the material on their own, in their own time. The main challenge was to come up with questions that were engaging enough (some were not, as is evident in the suggestions for improvement). The other challenge was in finding the time to mark the responses - no response was given at all even if students requested feedback, due to the number of responses received each week.

\section{Student Presentations}

The students generally enjoyed both making and hearing the class presentations (assignment 3 ).

Their comments included the following:

"It was good to hear different thoughts to those of the lecturers."

"They are a good method of obtaining skills in public speaking/presenting."

"Presentation is a good chance to present your ideas in front of others, and listening to the others can help you learn more."

"I got a lot of extra knowledge through the presentations."

"The presentations encourage students own view of topics."

"Some speeches were hard to understand - but worthwhile."

\section{Suggested Changes and General Comments}

Some suggestions, from the students, for changes to the subject for next semester were:

"Make the project management case study more straightforward."

"Include even more complexity in the case study for use with Microsoft Project. This was difficult at first, but when you got going was the best part of the course."

"The on-going project control exercises were really good - I learned a lot from them." 
"I got really frustrated with the project control exercises - I thought my project plan was good. But when I thought about them I think they are a really good idea. Include more next time.

"Create one case study chat room to exchange ideas and views. Maybe we can have a public folder where all of the best answers are published."

"Study the topic for next week's lecture instead of doing a search on the last lecture's topic. This way we can understand the next topic easier."

"Make the online work as a mini-case study where students will have to research online articles or any other source to solve the mini case. It can be a work group of 2-3 people. This will also foster students to work as a team and be more responsible."

"Perform more of these on-going project exercises to involve students more in the subject."

"The presentations were good, particularly giving a presentation yourself."

\section{Conclusion}

In our view, IT Project Management is a subject that should be included in all information systems courses, including those taken at a postgraduate level. We also advocate offering this, or a similar subject, to other business students. The number of IT projects that fail, and the increasing interest in project management by the industry and by professional IT societies make the inclusion of a subject related to this topic extremely important in university IT and business courses.

IT Project Management involves much more than just project planning and scheduling and is primarily concerned with controlling the on-going project during its whole life. Our research has shown that, despite some problems currently inherent in the use of project management software, it is quite possible to provide students with useful project management skills through the use of this software. We advocate the use of assignments based on adequate size, dynamic and on-going case studies to achieve this.

The online work enabled students to engage in the material in what seemed to some to be a novel way. Students themselves said that it enriched what they learnt. One can conclude that this positive experience was due to the students being given the opportunity to construct meaning for themselves by searching for information on some topics that they found interesting - most commonly the failure and success of projects. It seems that they preferred real-life examples that illustrated the abstract concepts involved in project management, because this was something they could relate to, as it is expected they at least had some experience with working in a dysfunctional group or a not-so-successful class project. The use of this assignment seems to be a good strategy for engaging students in the material. The main challenge would be in constructing the exercises and providing feedback and support to the students after submitting their answers.

It is always difficult to determine what someone else has learned, other than by asking or testing them. Our observations, and the surveys and test, however, suggest that the students did learn a number of things from this subject in addition to the subject content. They suggest that the students enhanced their problem solving skills and got a better idea of what managing a project involves from the assignment on project monitoring and control, and that they got a much better idea of the complexities of project management from this. The online exercises certainly helped to reinforce the lecture material, and this was appreciated by many of the students. The class presentations also forced students to focus on some of the important issues and to understand them sufficiently to be able to explain them to others.

Teaching IT Project Management is a challenging, but satisfying experience. The subject web page: http://www.business.vu.edu.au/bco6656/ contains further information about this subject. 


\section{References}

Australian Computer Society. (1997). The core body of knowledge for information technology professionals. Retrieved 20 Sept 1997 from http://www.acs.org.au/national/postpaper/bokpt1.htm

Biggs, J. (1999). Teaching for quality learning at university: What the student does. Buckingham: Society for Research in Higher Education and Open University Press.

Gorgone, J. T., Davis, G. B., Valacich, J. S., Topi, H., Feinstein, D. L. \& Longenecker, H. E. J. (2002). Model curriculum and guidelines for undergraduate degree programs in information systems. USA: Association for Information Systems.

Gorgone, J. T. \& Gray, P. (2000). MSIS 2000 - Model curriculum and guidelines for graduate degree programs in information systems. Communications of the Association for Information Systems, 3(1).

A guide to the project management body of knowledge ( $3^{\text {rd }}$ ed.). (2004). Newton Square, PA: Project Management Institute.

Hosseini, J. (1993). Application of Bloom's taxonomy and Piaget model of cognitive processes to teaching of management information systems concepts. Journal of Information Systems Education, 5(3).

Little, S. E. \& Margetson, D. B. (1989). A project-based approach to information systems design for undergraduates. The Australian Computer Journal, 21(2), 131.

McCarthy, J. (2004). Myths of IT. Information Age, October/November, 43-50.

Piaget, J. (1974). Understanding causality. New York: Norton.

Reyes, G. \& Gabb, R. (in press). Using ICT in a problem-based learning approach. In T. van Weert \& A. Tatnall, Information and communication technologies and real-life learning - New education for the knowledge society. New York: Springer/IFIP.

RMIT University (2005). 'Systems analysis and design II' subject guide. Retrieved April 2005 from http://www2.rmit.edu.au/resources/progstruct/BP138.html

Shackleton, P. \& Tatnall, A. (1995). Dynamic project management assignments. Australian Conference on Information Systems (ACIS-95), Perth.

Tatnall, A. \& Shackleton, P. (1993). Project management tools - Moving decision making from the emotional to the rational. ASCILITE' 93 , Lismore, University of New England.

Tatnall, A. \& Shackleton, P. (1995). Project management software: The fourth tool? Software Education Conference: SRIG-ET'94, Dunedin, New Zealand: IEEE Computer Society Press.

Tatnall, A. \& Shackleton, P. (1996). IT project management: Developing on-going skills in the management of software development projects. Software Engineering: Education and Practice, Dunedin, New Zealand: IEEE Computer Society Press.

Turner, R. (1993). The handbook of project-based management. London: McGraw-Hill.

van Weert, T. \& Tatnall, A., Eds. (in press). Information and communication technologies and real-life learning - New education for the knowledge society. New York: Springer/IFIP.

Victoria University (2005). ‘Systems design' subject guide. Retrieved April 2005 from http://www.businessandlaw.vu.edu.au/info_sys/Display_Subject_Guide.asp?subnum=678\&schoolnum $\underline{=1}$

Xia, W. \& Lee, G. (2004). Grasping the complexity of IS development projects. Communications of the $A C M, 47(5), 69-74$. 


\section{Appendix: Assignment 1 (Project Case Study)}

You have just been appointed as Project Manager for the consulting company: Information Systems Implementation Services Pty Ltd (ISIS) after the retirement of the previous project manager. ISIS has been in the IT business now for over 25 years and has gained a good deal of expertise in project management. ISIS is organised around projects and has three semi-autonomous divisions:

- The Implementation Group conducts most 'normal' projects which do not involve large amounts of programming or database work. It is managed directly by the Project Manager.

- The Special Systems Development Group, as its name suggests, is only involved in special projects involving a lot of programming and development. This group is managed by its Team Leader and its operations are overseen by the Project Manager.

- The Database Group specialises in data modelling, programming, data entry and the implementation of database projects. This group is managed by its Team Leader and its operations are overseen by the Project Manager.

\section{Case Study: Paramount Business Consultants}

Paramount Business Consultants Pty Ltd is a group of twenty-five consultants specialising in strategic planning, financial planning, change management and corporate governance. The group has been operating from their Melbourne offices in Collins Street for over forty years and is a highly respected company with a long list of important clients. The company is now headed by Richard Goldbury after the recent retirement of Edward Corcoran.

Under Mr Corcoran the company operated the way it had for the last forty years: by using manual systems, a typing pool and lots of filing cabinets. Mr Goldbury is determined to bring things up to date and has just purchased Bluetooth-enabled mobile phones for all consultants. He has engaged your company, Information Systems Implementation Services, to install a new information system. As the newly appointed Project Manager it will be your job to plan and then implement this project. Mr Goldbury has requested that the project be complete and operational by $1^{\text {st }}$ June.

\section{Project Requirements}

Paramount Consultants have the following information system requirements at this time:

- Install a network of computers in each professional and administrative office. The network operating system should be Novell.

- Mr Goldbury does not know much about computers but thinks that PCs running Windows XP Professional would be appropriate. He is keen that only 'the best' machines be used and has requested that you supply only IBM computers and HP printers. There are twenty-five consultants (including $\mathrm{Mr}$ Goldbury) and ten assistants (each of whom will need a computer). The administrative office is to be re-organised (- after most of the ten typists are retrenched) and will have a total of five administrative staff. Mr Goldbury thinks that each of these staff should have their own computer. Each of the consultants (and assistants) will also need their own (small) laser printer. The administrative office will require two larger, faster laser printers with several paper trays. The building in which Paramount are housed is quite old, but provision can be made for network cables in the ceiling. There is no room suitable for a network server but Mr Goldbury will authorise some building work to convert a storeroom for this purpose.

- Install Microsoft Office XP (Professional) software on all computers.

- Install broadband Internet access (via Optus cable) and ensure all computers in the network have Internet access.

- A set of Excel VBA spreadsheets macros to make up the information system that will be used by the consultants in planning their work. Mr Goldbury has detailed the requirements here and you will write these macros in Visual Basic for Applications (VBA).

- Install a new accounting system using MYOB. Access to this system should be available to two administrative staff to send invoices, enter payments and print accounting reports.

- Create a simple Web page advertising the company's presence.

- Most consultants often work from the premises of their clients and, although they try to take all relevant documentation with them, sometimes need additional files from the office. The system should al- 
low them to download these files while 'on the road', using Internet access via a laptop. Purchase five Bluetooth-enabled laptop computers (IBM) and set up connections to the mobile phone of each consultant. Set up access, via the Internet, to relevant files in the office.

- Organise and oversee training of all professional and administrative staff on the new system.

Further details and background information are also provided to the students. They are also provided with details of resource capabilities and costs, working times, hardware/software requirements etc. The above provides only a sample of this.

\section{Assignment 1a (Project Charter)}

Your project charter outlines the most important aspects of the project. You should use the Project Charter template (- see subject web site http://www.business.vu.edu.au/bco6656/). The Charter should include: project objective, business case, approach, roles and responsibilities, estimates, schedule (outline), budget (outline), project risks, and comments.

\section{Assignment 1b (The Project Plan)}

You should ensure that your project has no over-allocated resources, or dangling tasks. Before submission you should save the project with a baseline. You should include:

- A letter and firm quotation to Paramount Consultants. This letter should summarise the important items in the budget and schedule, and indicate any important dates - such as when cabling work is to occur, when training is planned and when the project is to be completed. It should, however, include only information that is relevant to Paramount Consultants, and be expressed in a form that will be readily understood.

- A memo to your boss, the Director or ISIS, including: table of contents and executive summary, a list of any assumptions you have made, and any special requirements for the project, a detailed Gantt chart showing the critical path, with a baseline project schedule, a Network diagram (PERT chart) with no dangling tasks: that is, every task should be on a path from the first to last task, a Microsoft Project summary report, a series of other reports showing detailed costing, and resource usage.

\section{Assignment 1c (Project Monitoring and Control)}

Each week the management team from ISIS meets to discuss progress of all projects. These meetings are held at 10:00 each Friday, and you will be given a report at the lecture of what was discussed.

The Director of ISIS requires you to update all tasks mentioned in the report (up to the date of the report i.e. $7^{\text {th }}$ May etc) and to make any required changes to the project schedules. In this monitoring task he requests copies of the following reports/charts for all projects for the next management meeting. (These should be submitted before your tutorial in the following week.)

- Tracking Gantt Chart

- Summary Report

- Budget Report

- Report on Slipping Tasks

You should also check for any over allocation of resources and correct this if necessary.

There are four monitoring/control tasks in this assignment, one given each week for the duration of the project. Students are given the tasks one at a time, each week. The first two of these tasks are shown below.

\section{Monitoring Task 1: (distributed to students $7^{\text {th }}$ May, due $14^{\text {th }}$ May)}

The project started on time at 0900 on Monday $3^{\text {rd }}$ May when the Blondini Brothers began their building work. This finished on time on Wednesday. Crawlers Cabling started work on Wednesday and should have no trouble finishing this afternoon. Work commenced (this morning) on the Excel macros and web page.

There was a problem, however, with purchasing of the PC equipment. It took longer than expected to finalise arrangement with the supplier and delivery has been delayed till 1100 Monday $10^{\text {th }}$ May. We don't then expect any further difficulties with supply. The project got off to a pretty good start! 


\section{Monitoring Task 2: (distributed to students $14^{\text {th }}$ May, due $21^{\text {st }}$ May)}

Programming the Excel macros and creating the web page went to plan. After some difficulty at the start, the hardware purchasing and checking was completed on time (as re-scheduled last week). Installation of Windows XP Professional, however, was done more quickly than expected, taking only 15 hours instead of the 20 hours allowed. As the Windows installation finished early, the network installation tasks were able to commence a little ahead of schedule. All work proceeded according to plan and, apart from the Broadband installation that has just commenced all these tasks are now complete (as per estimate).

Yesterday ( $13^{\text {th }}$ May) Mr Goldbury came to us with a request: he would like us to do some extra work in the project. He wants us to set up an Access database of Paramounts' clients (Microsoft Access was installed as part of Microsoft Office Professional). This is a fairly simple task and we have agreed to the request and promised to provide him with details of the additional costs. We have estimated that this work will require the services of an ISIS database modeller for 2 hours, and use of a clerical officer for 4 hours. (You should also allocate yourself $10 \%$ to this task.) This work can be done at any time after the network is operational but must be finished before project completion.

Mr Goldbury has also requested that the project be completed by $28^{\text {th }}$ May. Fortunately, you have just noticed that 'Training for Professional Staff' could start one day earlier. This task was intended to start 2 days after the installation of all software, but it is in fact scheduled to commence 3 days later due to the holiday on $20^{\text {th }}$ May (27FS $\left.+2 \mathrm{~d}\right)$. This is because the default in Microsoft Project is to make this 2 working days. You should correct this to make these 2 elapsed days (i.e. 2ed). This should fix the problem and satisfy $\mathrm{Mr}$ Goldbury. (If it does not do so, or if subsequent changes again extend the completion date you may need to schedule some project work as overtime.)

\section{Biographies}
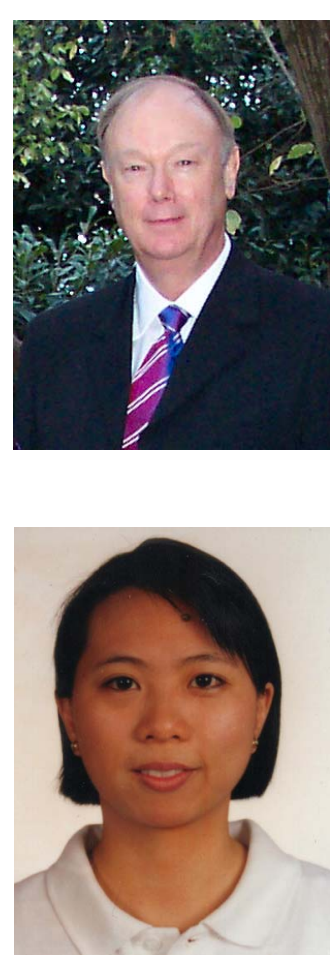

Arthur Tatnall is an Associate Professor in the Victoria Graduate School of Business at Victoria University in Melbourne, Australia. He holds bachelors degrees in Science and Education, a Graduate Diploma in Computer Science, and a research Master of Arts in which he explored the origins of Information Systems curriculum in Australian universities. His $\mathrm{PhD}$ involved a study in curriculum innovation in which he investigated the manner in which Visual Basic entered the curriculum of an Australian university. His research interests include technological innovation, information systems curriculum, project management, electronic commerce, and information technology in educational management. He has recently edited books on Web Portals and ICT and Real-Life Learning.

Gina Reyes is a Lecturer in the School of Information Systems at Victoria University in Melbourne, Australia. She holds undergraduate degrees in Computer Science and Management Science, a Graduate Certificate in Tertiary Education, and a Masters in Information Systems. She completed her PhD in Information Management at RMIT University, Melbourne, focussing on the impact of organisational context on the success of information systems departments. Her current research interests include effective e-learning strategies, the use of learning objects and case-based reasoning in learning systems, and constructive alignment in IS education 